\title{
Assessing a 600-mg Loading Dose of Clopidogrel 24 Hours Prior to Pipeline Embolization Device Treatment
}

\author{
Elias Atallah, MD \\ Thomas Jefferson University \\ Hassan Saad, MD \\ Thomas Jefferson University \\ Kimon Bekelis, MD \\ Thomas Jefferson University \\ Nohra Chalouhi, MD \\ Thomas Jefferson University \\ Stavropoula Tjoumakaris, MD \\ Thomas Jefferson University \\ Follow this and additional works at: https://jdc.jefferson.edu/jhnj \\ Let us know, how access to this document benefits you
}

\section{Recommended Citation}

Atallah, MD, Elias; Saad, MD, Hassan; Bekelis, MD, Kimon; Chalouhi, MD, Nohra; Tjoumakaris, MD, Stavropoula; Hasan, MD, David; Zarzour, MD, Hekmat; Smith, MD, Michelle; Rosenwasser, MD, MBA, FACS, FAHA, Robert H.; and Jabbour, Pascal MD (2018) "Assessing a 600-mg Loading Dose of Clopidogrel 24 Hours Prior to Pipeline Embolization Device Treatment," JHN Journal: Vol. 13 : Iss. 2 , Article 2.

DOI: https://doi.org/10.29046/JHNJ.013.2.002

Available at: https://jdc.jefferson.edu/jhnj/vol13/iss2/2

This Article is brought to you for free and open access by the Jefferson Digital Commons. The Jefferson Digital Commons is a service of Thomas Jefferson University's Center for Teaching and Learning (CTL). The Commons is a showcase for Jefferson books and journals, peer-reviewed scholarly publications, unique historical collections from the University archives, and teaching tools. The Jefferson Digital Commons allows researchers and interested readers anywhere in the world to learn about and keep up to date with Jefferson scholarship. This article has been accepted for inclusion in JHN Journal by an authorized administrator of the Jefferson Digital Commons. For more information, please contact: JeffersonDigitalCommons@jefferson.edu. 


\section{Assessing a 600-mg Loading Dose of Clopidogrel 24 Hours Prior to Pipeline Embolization Device Treatment}

\section{Authors}

Elias Atallah, MD; Hassan Saad, MD; Kimon Bekelis, MD; Nohra Chalouhi, MD; Stavropoula Tjoumakaris, MD; David Hasan, MD; Hekmat Zarzour, MD; Michelle Smith, MD; Robert H. Rosenwasser, MD, MBA, FACS, FAHA; and Pascal Jabbour MD 


\section{Assessing a 600-mg Loading Dose of Clopidogrel 24 Hours Prior to Pipeline Embolization Device Treatment}

\author{
Elias Atallah, MD; Hassan Saad, MD; Kimon Bekelis, MD; Nohra Chalouhi, MD; \\ Stavropoula Tjoumakaris, MD; David Hasan, MD; Hekmat Zarzour, MD; Michelle \\ Smith, MD; Robert H. Rosenwasser, MD, MBA, FACS, FAHA; Pascal Jabbour, MD \\ Department of Neurological Surgery, Thomas Jefferson University and Jefferson Hospital \\ for Neuroscience, Philadelphia, Pennsylvania, USA
}

\begin{abstract}
Background: Clopidogrel/aspirin antiplatelet therapy routinely is administered 7-10 days before pipeline aneurysm treatment. Our study assessed the safety and efficacy of a 600-mg loading dose of clopidogrel 24 hours before Pipeline Embolization Device (PED) treatment.

Methods: In this retrospective cohort study, we included patients treated with PED from October 2010 to May 2016. A total of $39.7 \%(n=158)$ of patients were dispensed a loading dose of $650 \mathrm{mg}$ of aspirin plus at least $600 \mathrm{mg}$ of clopidogrel 24 hours preceding PED deployment, compared to $60.3 \%(n=240)$ of patients who received $81-325 \mathrm{mg}$ of aspirin daily for 10 days with $75 \mathrm{mg}$ of clopidogrel daily preprocedurally. The mean follow-up was 15.8 months (standard deviation [SD] 12.4 months). modified Rankin Scale (mRS) was registered before the discharge and at each follow-up visit. To control confounding, we used multivariable logistic regression and propensity score conditioning.
\end{abstract}

Results: Of 398 patients, the proportion of female patients was $16.5 \%(41 / 240)$ in both groups and shared the same mean of age $~ 56.46$ years. $12.2 \%$ (mean $=0.09$; $\mathrm{SD}=0.30)$ had a subarachnoid hemorrhage. $92 \%$ (mean $=0.29 ; \mathrm{SD}=0.70)$ from the pretreatment group and $85.7 \%$ (mean $=0.44$; SD $=0.91$ ) of the bolus group had a $m R S \leq 2$. In multivariate analysis, bolus did not affect the $m R S$ score, $P=0.24$. Seven patients had a long-term recurrence, $2(0.83 \%$; mean $=0.01 ; S D=0.10)$ of which from the pretreatment group. In a multivariable logistic regression, bolus was not associated with a long-term recurrence rate (odds ratio [OR] 1.91; 95\% confidence interval [CI] 0.27-13.50; $\mathrm{P}=0.52$ ) or with thromboembolic accidents (OR 0.99; 95\% Cl 0.96-1.03; $P=0.83$ ) nor with hemorrhagic events (OR 1.00; 95\% Cl 0.97-1.03; $P=0.99$ ). Three patients died: one who received a bolus had an acute subarachnoid hemorrhage. The mean mortality rate was parallel in both groups $\sim 0.25$ (SD $=0.16$ ). Bolus was not associated with mortality (OR 1.11; 95\% Cl 0.26-4.65; P = 0.89). The same associations were present in propensity score-adjusted models.

Conclusions: In a cohort receiving PED, a 600-mg loading dose of clopidogrel should be safe and efficacious in those off the standard protocol or showing $<30 \%$ platelet inhibition before treatment.

\section{INTRODUCTION}

Pipeline embolization device (PED; Covidien, Irvine, California, USA) has become an integral tool in the treatment of intracranial aneurysms. Since its approval by the Food and Drug Administration in 2011, studies have publicized remarkable occlusion rates with this endoluminal device. ${ }^{1}$ Antiaggregation drugs are dispensed during and after the pipeline deployment procedure to reduce the likelihood of thromboembolic events. ${ }^{2}$ A single loading dose of aspirin or clopidogrel is neither safe nor sufficient in reducing PED-related thromboembolic complications. ${ }^{3}$ Patients suffering from cerebrovascular aneurysms and selected for a flow diversion treatment should receive a dual antiplatelet therapy (DAPT) of aspirin and clopidogrel for a minimum of 7-10 days before the intervention. ${ }^{4}$ Even at a high maintenance dose, patients continue to show variability in the degree of platelet inhibition. ${ }^{5}$

The key in approaching cerebral aneurysms is in assuring an optimal $>50 \%$ platelet inhibition with the right choice of antiplatelet medication and by keeping the platelet-reactive units (PRUs) between 194 and 416 (adopted in our center). ${ }^{6}$ Although a standard $75-\mathrm{mg}$ dose of clopidogrel produces an irreversible P2Y12 platelet receptor blockade, its 72-hour delayed maximal action is one of its major limitations. ${ }^{7}$ A bolus of 600 mg of clopidogrel must be administered to overcome the previous limitation and achieve a rapid and more potent platelet inhibition within 24 hours before the pipeline deployment. ${ }^{8}$ The central aim of this study was to evaluate the safety and the efficacy of a 600-mg loading dose of clopidogrel when given 24 hours before PED deployment to protect patients from thromboembolic events during and after their procedure.

\section{METHODS}

\section{Study Population}

This was a retrospective cohort study of all patients undergoing a PED treatment for their cerebrovascular aneurysms in a tertiary referral center between October 2010 and May 2016. A total of 398 consecutive patients undergoing pipeline flow diversion were included. The mean age of the population was 56.46 years ( $\min =16$ years, $\max =81$ years). Only 2 patients were minors at 16 and 17 years old. The study protocol was reviewed and approved by the institutional review board. Patient consent was not needed because of the retrospective nature of the study. A total of 23 of 398 patients presented with ruptured aneurysm. 


\section{Treatment Protocol}

Patients treated with the PED were analyzed retrospectively and separated into two groups of standard of care treatment, i.e., 158 (39.7\%) patients were administered a DAPT bolus of $650 \mathrm{mg}$ of aspirin plus at least $600 \mathrm{mg}$ of clopidogrel within the 24 hours preceding their procedure and 240 (60.3\%) patients (227 with aspirin, 9 with coumadin, 4 with rivaroxaban) received the standard protocol of $81-325 \mathrm{mg}$ of aspirin daily with $75 \mathrm{mg}$ of clopidogrel daily for 7-10 days before their intervention. Patients included in both groups were recruited subsequent to an incidental finding of their aneurysm on routine neuroimaging or to a screening magnetic resonance angiography prescribed because of first-degree family history of aneurysms. Others had symptoms related to the aneurysm: worst headache of life, Horner syndrome, worsening headache, ophthalmoplegia, dizziness, tinnitus, blurry vision, diplopia, and retroorbital pain. A total of $23(5.8 \%)$ patients were admitted urgently and diagnosed with a subarachnoid hemorrhage (SAH) secondary to aneurysm rupture: 6 (26\%) were pretreated with aspirin and clopidogrel, and 17 (74\%) was administered a bolus of DAPT as described previously.

We regularly calculated the P2Y12 PRU score using P2Y12 assays (VerifyNow; Accumetrics, San Diego, California, USA) for all patients before the procedure. Prasugrel $(n=20)$ was considered if the patients were allergic, nonresponders, or resistant to clopidogrel. Resistance was defined with $<30 \%$, PRU $<194$ of platelets' P2Y12 receptor inhibition with antiplatelet drugs. Ticagrelor $(n=2)$ was adopted in patients labeled as non- responders or allergic to prasugrel. Patients with inhibition $>90 \%$ had their procedure canceled, and clopidogrel was held until the platelet inhibition level fell below 90\%. Patients were continued afterword on $75 \mathrm{mg}$ of clopidogrel daily or 5-10 mg of prasugrel daily or $90 \mathrm{mg}$ twice a day of ticagrelor daily. Vitals and neurologic examination were monitored in the intensive care unit, and patients were deescalated to the floor after 24 hours of clinical well-being. Prophylactic antiplatelet therapy was given as a minimum of 6 months to 1 year after the procedure, followed by aspirin indefinitely (Figure 1).

\section{Outcome Variables}

The key primary outcomes were thromboembolic event incidence (minor: transient deficit or asymptomatic stroke documented on diffusion-weighted imaging; major: clinically measurable deficit) including pre- and postprocedural thrombus formation and hemorrhagic accidents with subsequent tangible and concrete clinical deficit (not including the asymptomatic sulcal $\mathrm{SAH}$ as seen on routine postoperational computed tomography) after pipeline deployment. Early and late postprocedural hemorrhagic and thromboembolic events were included. Modified Rankin Scale (mRS) score, calculated and registered before the discharge of the patients and at each follow-up visit, mortality rates, intrapipeline stenosis due to overt neoendothelialization, postinterventional length of stay, and the long-term recurrence were all considered secondary outcomes.

\section{Patient Follow-Up}

Follow-up visits were scheduled with the senior author after 1, 3, 6, and 18 months after their discharge from the institution. The efficacy and the safety of the aspirin/clopidogrel bolus dispensed within 24 hours preceding the pipeline treatment was evaluated on initial postoperative angiography. Cerebrovascular angiography (digital subtraction angiography) was required at the 6 -month visit, and then patients were followed accordingly to evaluate for bleeding recurrence or vessel stenosis. Computed tomography scans of the head were compared and analyzed by the senior author to document any new or recurrent subarachnoid or intraparenchymal hemorrhage only if the patients developed new insidious symptoms. Medical charts were reviewed to determine whether any retroperitoneal, gastrointestinal, or genitourinary bleeding had occurred.

\section{Exposure Variables}

The primary exposure variable was the treatment (clopidogrel pretreatment vs. clopidogrel bolus). Covariates used for risk adjustment were age and sex. The comorbidities used for risk adjustment

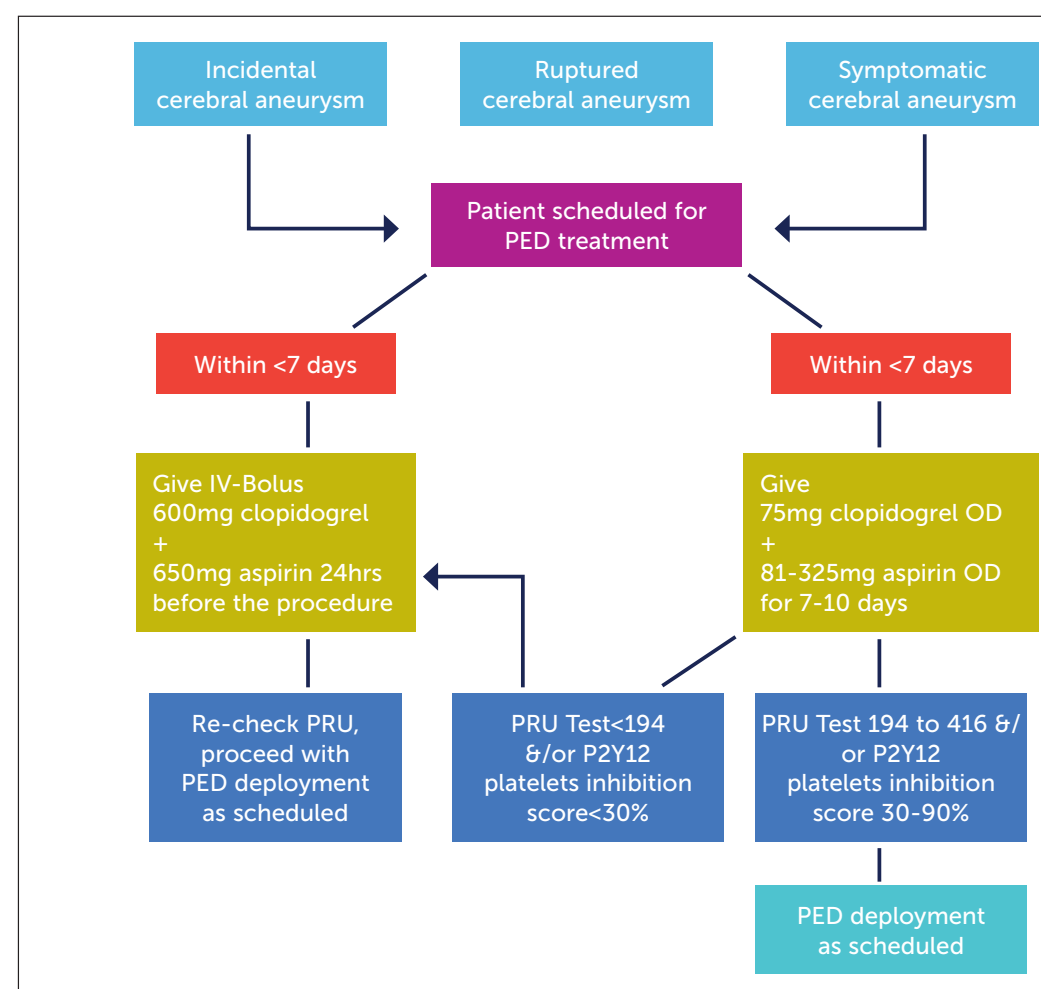

Figure 1. Decision tree graph of the antiaggregation Pipeline Embolization Device; PRU, platelet-reactive protocol adopted before pipeline deployment. PED, unit. 


\begin{tabular}{|l|c|c|c|}
\hline \multirow{2}{*}{ Table 1. Patient characteristics } & \multirow{2}{*}{ Bolus } \\
\hline & \multicolumn{2}{|c|}{ p value } \\
\cline { 2 - 3 } & Yes (n=158) & No (n=240) & 0.51 \\
\hline Age (years) & $56.77(13.70)$ & $56.15(13.04)$ & 0.30 \\
\hline Male gender & $84.2 \%$ & $82.9 \%$ & 0.83 \\
\hline Hypertension & $0.53(0.50)$ & $0.49(0,50)$ & 0.31 \\
\hline Smoking & $0.52(0.50)$ & $0.49(0,50)$ & 2.86 \\
\hline Aneurysm size (mm) & $9.58(6.84)$ & $9.23(6.04)$ & 0.92 \\
\hline Previous SAH & $0.10(0.30)$ & $0.10(0.23)$ & 0.75 \\
\hline Adjunctive Coiling & $0.12(0.33)$ & $0.04(0.20)$ & 0.90 \\
\hline Balloon use & $0.07(0.26)$ & $0.07(0.26)$ & \\
\hline
\end{tabular}

*SAH, subarachnoid hemorrhage.

were hypertension, diabetes mellitus, smoking, previous SAH, aneurysm size, per-procedural balloon, previous coiling. This manuscript adheres to the Strengthening the Reporting of Observational studies in Epidemiology (i.e., STROBE) Statement: guidelines for reporting observational studies.

\section{Statistical Analysis}

For binary outcomes we used a multivariable logistic regression, controlling for all the covariates mentioned previously. To control for clustering at the physician level, we used mixed effect models with physician as a random effects variable. For continuous outcomes, we used the corresponding linear regression analyses.

In an alternate way to control for confounding for binary outcomes, we used a propensity score adjusted logistic regression model. To derive the propensity of receiving a bolus, we developed a prediction model using logistic regression, based on all the covariates described previously. We subsequently used a logistic regression with adjustment (stratification) by quantiles (we chose the number of quantiles to be 10) of the propensity score. Operating physician was again used as a random effects variable.

Patients who were lost to follow-up were not included in the original analysis. In sensitivity analysis, all the aforementioned analyses were repeated used multiple imputations for the patients lost to follow-up.
Regression diagnostics were performed for all analyses. Given that the long-term recurrence was $2 \%$ in a study sample of 437 patients, we had an $80 \%$ power to detect a difference in long-term recurrence as small as $13.4 \%$, at an $\alpha$-level of 0.05 . All probability values were the result of two sided tests. Stata version 13 (StataCorp, College Station, Texas, USA) was used for statistical analysis.

\section{RESULTS}

\section{Demographic Characteristics}

Between October 2010 and May 2016, 398 patients underwent treatment with PED in our institution. The proportion of female patients was $17.1 \%(41 / 240)$ in the pretreatment group and 15.8\% (25/158) in the bolus group ( $P=0.30$ ). Patients in the pretreatment group shared a similar mean of age with the bolus group (56.15 years; 56.77 years), respectively $(P=$ 0.510). The mean aneurysm size was 9.22 $\mathrm{mm}$ (standard deviation [SD] $=6.04$ ) in the pretreatment group and $9.58 \mathrm{~mm}$ (SD $=6.84)$ in the bolus group $(P=2.86)$. The proportion of patients with a history of previous SAH (not presenting with acute $\mathrm{SAH})$ was $11.7 \%$ (28/240; mean $=0.09$; $\mathrm{SD}=0.30)$ in the pretreatment group, whereas it was $12.7 \%(20 / 158$; mean = 0.10 ; $S D=0.30)$ in the bolus group $(P=$ 0.92). Likewise, both groups had the same average $1.21(\min =1$ PED, $\max =4$ PED) number of pipelines used per patient. The fraction of patients receiving adjunctive coiling was 4.6\% (11/240; mean $=0.41$;
$\mathrm{SD}=0.19)$ in the pretreatment group versus $13.3 \%(20 / 158$; mean $=0.12 ; S D$ $=0.33$ ) in patients receiving the loading dose of antiaggregate medication ( $P=$ $0.75)$. Balloon angioplasty was needed in approximately $9.7 \%(22 / 240 ; 16 / 158)$ of patients in both groups $(P=0.90)$. Nine of 158 patients from the bolus group presented with aneurysm rupture and a subsequent $\mathrm{SAH}$ and required an immediate intervention with a loading dose of clopidogrel. A total of 139 of 158 patients were included because of nonresponsiveness or resistance to the standard 10 days DAPT antiaggregation protocol. The mean monthly follow-up for the patients was 15.8 months (SD = 12.36). A total of 398 patients were identified at our institution, and they constituted our study population. The characteristics of the cohort at baseline are disclosed in Table 1 .

\section{Safety of a Loading Dose of Clopidogrel}

Thromboembolic Complications. Of 398 patients, 15 (6.3\%; mean $=0.05$; SD = $0.23)$ patients receiving the pretreatment protocol had thromboembolic complications, and 17 (10.8\%; me an $=0.12 ; \mathrm{SD}=0.32$ ) patients from the bolus group suffered from these complications (Table 2). A univariate analysis comparing the use of a bolus of clopidogrel with the thromboembolic complication rate did not show any correlation between the 2 variables (odds ratio [OR], 0.99; 95\% confidence interval [Cl] 0.96-1.03; $P$ $=0.83)$. We found similar results in a multivariable mixed-effects logistic regression bolus (OR 0.99; 95\% Cl $0.96-1.03 ; P=0.81$ ) and a propensity score-adjusted model (OR 0.99; 95\% Cl 0.96-1.03; $P=0.82$ ).

Hemorrhagic Complications. Of 398 patients, 9 (3.75\%; mean $=0.25$; SD = 0.16 ) (Table 2) patients receiving the pretreatment protocol had hemorrhagic complications, and 12 (7.6\%; mean $=0.08 ;$ SD $=0.27$ ) patients from the bolus group suffered from these complications. The mean of hemorrhagic complications in the global population was 0.48 (SD $=0.21$ ). A univariate analysis comparing the use of a bolus of clopidogrel with the hemorrhagic complication rate did not show any correlation between the 2 
variables (OR 0.99; 95\% Cl 0.97-1.03; $P=0.87)$. In a multivariable mixedeffects logistic regression, bolus (OR 1.00; 95\% Cl 0.97-1.03; $P=0.99$ ) was not associated with an increased hemorrhagic event rate. We found similar results with the propensity score adjusted model (OR 0.99; 95\% Cl 0.96-1.03; $\mathrm{P}=0.87$ ).

Long-Term Recurrence. Of 398, $7(1.76 \%$; mean $=0.02 ; \mathrm{SD}=0.15)$ patients had a long-term recurrence: 2 $(0.83 \%$; mean $=0.01 ; \mathrm{SD}=0.10)$ from the pretreatment group versus 5 (3.16\%; mean $=0.03$; $S D=0.18$ ) patients in the bolus group. A univariate analysis comparing the use of a bolus of clopidogrel to the long-term recurrence rate did not show any correlation between the 2 variables (OR 3.32; 95\% Cl 0.60-18.43; $P=0.17$ ). In a multivariable mixed-effects logistic regression, 0.52 ) was not associated with a longterm recurrence rate. This finding was consistent with the propensity scoreeadjusted model (OR 3.00; $95 \% \mathrm{Cl}$ 0.51-17.58; $P=0.22$ ) (Table 3). bolus (OR 1.91; 95\% Cl 0.27-13.50; $\mathrm{P}=$

Mortality. Of 398 patients, 9 patients expired: 6 patients died from various non-PED related events such as severe sepsis (1), malignant hypertension with a large middle cerebral artery infarct (1), severe gastro-intestinal complication (1), and non-reported (3). Only three patients were announced dead secondary to cerebrovascular complications: one patient from the bolus group died from acute $\mathrm{SAH}$, and two patients from the pretreatment group died from severe intraparenchymal hemorrhage. The mean of mortality rate in the global population was 0.02 (SD = 0.15), 0.25 (SD = 0.16) in the pretreatment group, and 0.26 (SD $=0.16$ ) in the bolus group (Table 2). A univariate analysis comparing the use of a bolus of clopidogrel to the mortality rate did not show any correlation between the two variables (OR 0.99; 95\% Cl 0.77-1.30; $P=0.95)$. In a multivariable mixed-effects logistic regression, bolus (OR 1.11; $95 \% \mathrm{Cl}$ 0.26-4.65; $P=0.89$ ) was not associated with an increased mortality rate. This finding persisted in a propensity

Table 2. Mean Value and Standard Deviation of Outcomes

\begin{tabular}{|l|c|c|c|}
\hline Outcomes & $\begin{array}{c}\text { Pre-treatment } \\
\text { mean(SD*) }\end{array}$ & $\begin{array}{c}\text { Bolus } \\
\text { mean(SD* }\end{array}$ & $\begin{array}{c}\text { Total } \\
\text { mean(SD* }\end{array}$ \\
\hline Long-term recurrence & $.11(0.10)$ & $.34(0.2)$ & $.21(0.14)$ \\
\hline Intra-PED stenosis & $.07(0.26) \mathrm{n}=17$ & $0.07(0.26) \mathrm{n}=10$ & $.07(0.26)$ \\
\hline Thromboembolic acc. & $.54(0.23) \mathrm{n}=2$ & $.12(0.32) \mathrm{n}=5$ & $.07(0.26)$ \\
\hline Hemorrhagic acc. & $.25(0.16)$ & $.10(0.28$ & $.41(0.28)$ \\
\hline Mortality & $.25(0.16)$ & $.25(0.16)$ & $.02(0.15)$ \\
\hline Length of stay(days) & $1.69(2.81)$ & $2.11(3.2)$ & $1.86(2.96)$ \\
\hline mRS at last follow-up & $.44(0.91)$ & $.29(0.7)$ & $.36(0.79)$ \\
\hline
\end{tabular}

*SD, standard deviation; PED, Pipeline Embolization Device; acc., accident; mRS, modified Rankin Scale. score-adjusted model (OR 0.99; 95\% $\mathrm{Cl} 0.89-1.11 ; \mathrm{P}=0.92$ ).

\section{Efficacy of the Loading Dose of Clopidogrel}

Intrapipeline Stenosis. Of 398 patients, $27(6.8 \%$; mean $=0.75 ; \mathrm{SD}=0.26)$ had an intra-PED stenosis with 17 (7.08\%; mean = $0.72 ; \mathrm{SD}=0.26)$ in the pretreatment group and $10(6.32 \%$; mean $=0.76 ; S D=0.27)$ in the bolus group. A univariate analysis comparing the use of a bolus of clopidogrel with the intrapipeline stenosis rate did not show any correlation between the two variables (OR 1.07; 95\% Cl 0.45-2.55; $P=0.88)$. In a multivariate mixed-effects logistic regression, bolus (OR, 0.90; 95\% $\mathrm{Cl} 0.36$-2.30; $\mathrm{P}=0.89$ ) was not associated with higher intra-PED stenosis rate. This was coherent with the propensity score-adjusted model. (OR 0.92; 95\% Cl 0.37-2.34; $\mathrm{P}=0.88$ ).

Latest Clinical Status. In the global population, the mean mRS was 0.36 (SD = 0.79); it was $0.44(S D=0.91)$ in the bolus group and $0.29(\mathrm{SD}=0.70)$ in the pretreatment group. A total of $87.8 \%$ of the global population, $92 \%$ of the pretreatment group and $85.7 \%$ of the bolus group had a mRS 2 . In a multivariate analysis were the latest $\mathrm{mRS}$ is a dependent variable, bolus did not affect the latest mRS score, $\mathrm{P}=0.24$ (Table 3).

Postinterventional Hospital Stay. In the global population, the mean postoperational hospital stay was 1.86 days (SD = 2.96): 1.69 days ( $S D=2.81$ ) in the pretreatment group and 2.11 days (SD = 3.2) in the bolus group. In a multivariate analysis in which the postinterventional stay is a dependent variable, bolus did not affect the postoperational hospital stay, $\mathrm{P}=0.64$.

Table 3. Aassociation Between Outcomes and Clopidogrel Bolus

\begin{tabular}{|c|c|c|c|c|c|c|c|c|c|c|}
\hline \multirow{3}{*}{\begin{tabular}{l}
\multicolumn{1}{c}{ Models } \\
Multi-variable \\
logistic regression
\end{tabular}} & \multirow{2}{*}{\multicolumn{2}{|c|}{$\begin{array}{l}\text { Long-term recurrence } \\
\mathrm{OR}^{*}(\mathrm{C} \mid 95 \%) \quad p \text { value }\end{array}$}} & \multirow{2}{*}{\multicolumn{2}{|c|}{$\begin{array}{l}\text { Intra-PED stenosis } \\
\mathrm{OR}^{*}(\mathrm{C} \mid 95 \%) \quad p \text { value }\end{array}$}} & \multicolumn{2}{|c|}{ Thromboembolic } & \multicolumn{2}{|c|}{ Hemorrhagic } & \multicolumn{2}{|c|}{ Mortality } \\
\hline & & & & & $\mathrm{OR}^{*}(\mathrm{Cl} 95$ & value & $\mathrm{OR}^{*}(\mathrm{Cl} 95$ & p value & $\mathrm{OR}^{*}(\mathrm{Cl} 95$ & $\mathrm{p}$ value \\
\hline & $\begin{array}{c}1.91 \\
(.27 \text { to } 13.50)\end{array}$ & 0.517 & $\begin{array}{c}0.90 \\
\text { (.36 to } 2.29)\end{array}$ & 0.83 & $\begin{array}{c}0.99 \\
\text { (.96 to } 1.03)\end{array}$ & 0.81 & $\begin{array}{c}1.00 \\
\text { (.97 to } 1.03)\end{array}$ & 0.99 & $\begin{array}{c}1.11 \\
\text { (.26 to } 4.65)\end{array}$ & 0.89 \\
\hline Propensity score & $\begin{array}{c}3.00 \\
\text { (.513 to } 17.58)\end{array}$ & 0.22 & $\begin{array}{c}0.928 \\
(.37 \text { to } 2.34)\end{array}$ & 0.88 & $\begin{array}{c}0.99 \\
(.96 \text { to } 1.03)\end{array}$ & 0.82 & $\begin{array}{c}0.99 \\
(.97 \text { to } 1.03)\end{array}$ & 0.87 & $\begin{array}{c}0.99 \\
(.89 \text { to } 1.11)\end{array}$ & 0.92 \\
\hline
\end{tabular}

*OR, odds ratio; $\mathrm{Cl}$, confidence interval. 


\section{DISCUSSION}

Using a retrospective cohort of patients treated for their cerebrovascular aneurysm(s), we did not find any association between a clopidogrel 600-mg loading dose and increased mortality rate, thromboembolic accidents, longterm recurrence, intrapipeline stenosis, hemorrhagic events, mRS on last followup, and postoperational length of stay. The elevated risk of acute and delayed thromboembolic complications associated with the PED necessitates the use of antiplatelet therapy. ${ }^{9}$ The use of DAPT instead of aspirin alone has been the most commonly used trend after being translated from the cardiology literature. ${ }^{10}$ Nevertheless, there is no standard protocol to define the dose, duration, and the combination of the antiplatelet drugs used in the setting of PED placement. ${ }^{11}$

In our study, $10.8 \%$ of patients in the bolus group suffered from thromboembolic complications compared with $6.3 \%$ of the maintenance group. A total of 17 patients from the bolus group manifested with thromboembolic events within less than 1-month follow-up: only 4 of them had a major permanent neurologic deficit ranging from extremity weakness to complete hemiparesis, whereas the other 13 patients had minor transient neurologic symptoms, such as visual floaters, minimal limb weakness, and numbness or speech difficulty, that completely resolved on latest follow-up $(m R S<1)$. The latter results are somehow predictable as they reflect the pharmacodynamic properties of clopidogrel. Platelet function assays done ex vivo revealed a measurable antiplatelet effect starting within 60 minutes and reaching a maximum of antiplatelet inhibition 2 hours after the 600-mg loading dose of clopidogrel. ${ }^{12-14}$ The rates of thromboembolic events seen in the clopidogrel bolus group would be precipitated by the complex pathophysiology of thromboembolic events even when the patient is under an optimal antiplatelet regimen. This clopidogrel regimen would be addressing one single step in the primary hemostasis (platelet aggregation) process and sometimes might turn out to be insufficient for complete and definite protection of the patient from these complications.
The rate of hemorrhagic complications in the clopidogrel bolus group was $7.6 \%$ compared with $3.75 \%$ in the clopidogrel pretreatment maintenance dose. Leung et al. ${ }^{15}$ suggested that patients with acute ischemic strokes receiving clopidogrel loading doses within 24 hours of symptom onset did not have a greater rate of new serious bleeding events compared with patients who did not receive loading doses. Nonetheless, we will wait the results of the PlateletOriented Inhibition in New TIA and Minor Ischemic Stroke trial to confirm the safety of clopi- dogrel dosing in this group. ${ }^{16}$ Nonetheless, 4 patients receiving bolus precipitated intracerebral hemorrhage postprocedurally. One died, and 3 had small right temporal and frontal bleeding, who ended up having minimal neurologic sequelae (mRS 2). Eight other patients from the same group manifested SAH postprocedurally. Three had minor SAH with minimal neurosequelae (mRS 2) on latest follow-up, and the remaining 5 patients died subsequently due to major SAH: 2 of them died the first week after their intervention, and the last 3 died 1 or 2 months postprocedurally. Even if our statistical analysis does not show any significant difference in hemorrhagic complication between both groups, it is noteworthy to emphasize the greater rate of hemorrhagic events in the bolus group. Whether the clopidogrel loading dose increased the rate of hemorrhage in our series cannot be inferred from our descriptive study design, and further prospective studies are needed for to confirm these observations.

To our knowledge, there is only one study reflecting a head-to-head comparison between clopidogrel pretreatment protocol and high loading dose in cardiovascular literature, as percutaneous coronary intervention $(\mathrm{PCl})$ is almost always done during emergencies.17 In this randomized, double-blinded, clinical trial, Nguyen et al. ${ }^{17}$ compared different maintenance doses of clopidogrel given a week before $\mathrm{PCl}$ (75 mg once daily vs. 150 mg once daily after 300-mg loading dose each) and loading doses (300 mg vs. $600 \mathrm{mg}$ ) given 1 day before the procedure. They concluded that a loading standard dose of $300 \mathrm{mg}$ of clopidogrel followed by a 150-mg daily maintenance dose given a week before $\mathrm{PCl}$ achieved better platelet inhibition and low reactivity than the 300-mg loading dose given 24 hours before the procedure. How- ever, the 600-mg loading dose given a day before $\mathrm{PCl}$ was not statistically inferior to the 300-mg/150-mg daily maintenance dose.

The results from the Antiplatelet therapy for Reduction of Myocardial Damage during Angioplasty (ARMYDA-8 RELOAD- ACS) trial have shown a statistically significant advantage of reloading patients with acute coronary syndrome who were already on chronic clopidogrel therapy ( $75 \mathrm{mg}$ ) with a loading dose of $600 \mathrm{mg}$ of clopidogrel before $\mathrm{PCl} .{ }^{18}$ The reloading strategy was associated with a $66 \%$ relative risk reduction of 30 -day major adverse cardiac events. ${ }^{18}$ Whether this additional advantage is due exclusively to added inhibition of platelet aggregation is not well established. A study conducted by Patti et al. ${ }^{19}$ indicates that a clopidogrel loading dose $(600$ $\mathrm{mg}$ or $300 \mathrm{mg}$ ) before $\mathrm{PCl}$ decreases procedural $\mathrm{P}$-selectin levels. P-selectin is a marker of platelet activation and may directly contribute to the stability of platelet aggregates. ${ }^{20}$ It also may be partly responsible for mechanisms linking inflammation and thrombosis. ${ }^{21}$ This may suggest that the benefits of the loading dose strategy are not just exclusive to the inhibition of adenosine diphosphateeinduced platelet aggregation. Many other studies demonstrated the advantage of giving a high-loading dose $(600 \mathrm{mg})$ of clopidogrel before $\mathrm{PCl}$ compared with the standard 300-mg dose. ${ }^{19,22-24}$ Also, the clinical trial done by Nguyen et al. did not show any superiority of an even high pretreatment maintenance dose of clopidogrel preceded by $300-\mathrm{mg}$ bolus 1 week before $\mathrm{PCl}$ compared with the 600-mg loading dose 1 day before the procedure. ${ }^{17}$ It is also noteworthy to mention that in our study population, $<20 \%$ of the patients were female, and our overall aneurysm distribution by sex was not typically skewed towards males. We do not know how this finding could have affected our results. Further prospective studies are needed to uncover a possible association between sex and pipeline treatment complications.

Whether all these results infer superiority of the 600-mg loading dose of clopidogrel before PED to the 75-mg maintenance dose given a week before

14 
the procedure cannot be determined at this time. Most of the studies in which authors compared the efficacy and safety of different doses of clopidogrel were extrapolated from cardiac studies and cannot be directly translated to cerebrovascular settings. Also, no headto-head comparison was done between the 1-week pretreatment maintenance dose of clopidogrel with the 600-mg loading dose 24 hours before PED. This comparison was not done in the present study, and no definite conclusions can be derived at this point. Our study is the first descriptive observational study that compared the different outcomes between the 600-mg loading dose and the pretreatment $75-\mathrm{mg}$ maintenance dose used in patients undergoing PED. Our study remains limited by the retrospective nature of the data collection: the patients were not selected randomly for bolus versus pretreatment. Such a limitation must be addressed in further large prospective studies. Although no direct clinical suggestions can be derived from this study, we believe it is a first step towards higher-evidence studies to come out with a standard regimen of DAPT.

\section{CONCLUSIONS}

Aspirin/clopidogrel DAPT routinely is recommended for patients $7 e 10$ days before receiving neurovascular PED treatment. Never- theless, patients presenting with ruptured aneurysms, those who could have not received a standard 10 days DAPT protocol, or those showing nonsatisfactory platelet inhibition at admission can be selected for an acute antiaggregation protocol: a 600-mg loading dose of clopidogrel might be safe and efficacious in reaching the optimal platelet inhibition within 24 hours of the pipeline deployment.

\section{REFERENCES}

1. Linfante I, Mayich M, Sonig A, Fujimoto J, Siddiqui A, Dabus G. Flow diversion with Pipeline Embolic Device as treatment of subarachnoid hem- orrhage secondary to blister aneurysms: dual-center experience and review of the literature. J Neurointerv Surg. 2017;9:29-33.

2. Chalouhi N, Tjoumakaris S, Phillips JL, Starke RM, Hasan D, Wu C, et al. A single pipe- line embolization device is sufficient for treatment of intracranial aneurysms. AJNR Am J Neuroradiol. 2014;35:1562-1566.

3. Skukalek SL, Winkler AM, Kang J, Deon JE, Cawley CM, Webb A, et al. Effect of antiplatelet therapy and platelet function testing on hemor- rhagic and thrombotic complications in patients with cerebral aneurysms treated with the pipeline embolization device a review and meta-analysis. J Neurointerv Surg. 2016;8:58-65.

4. Rossen JD, Chalouhi C. Incidence of cerebral ischemic events after discontinuation of clopidogrel in patients with intracranial aneurysms treated with stent-assisted techniques. J Neurosurg. 2012;117:929-933

5. Awad AR, Alqahtani M, Gordon MOE. Clopidog- rel resistance. Cardiol Round. XIII, 2008

6. Delgado Almandoz JE, Kadkhodayan Y, Crandall BM, Scholz JM, Fease JL, Tubman $D E$. Variability in initial response to standard clopi- dogrel therapy, delayed conversion to clopidogrel hyper-response, and associated thromboembolic and hemorrhagic complications in patients undergoing endovascular treatment of unruptured cerebral aneurysms J Neurointerv Surg. 2014;6: 767-773.

7. Zaidat $\bigcirc$ O. Periprocedural management of pa- tients with endovascular treatment of intracranial atherosclerotic disease. $\mathrm{J}$ Neuroimaging. 2009; 19(suppl 1):35S-38S

8. Cuisset T, Frère C, Quilici J, Morange PE, Saidi LN, Carvajal J, et al. Beneficial effect of a loading dose of $600 \mathrm{mg}$ of clopidogrel on platelet parameters in patients admitted for acute coro- nary syndrome. Arch Mal Coeur Vaiss. 2006;99: 889-893 [in French].

9. Gupta R, Moore JM, Griessenauer CJ, Adeeb N, Patel AS, Youn R, et al. Assessment of dual antiplatelet regimen for pipeline embolization device placement: a survey of major academic neurovascular centers in the United States. World Neurosurg. 2016;96:285-292.

10. Gouya G, Arrich J, Wolzt M, Huber K, Verheugt FWA, Gurbel PA, et al. Antiplatelet treatment for prevention of cerebrovascular events in patients with vascular diseases: a systematic review and meta-analysis. Stroke. 2014; $45: 492-503$
11. Faught RW, Satti SR, Hurst RW, Pukenas BA, Smith MJ. Heterogeneous practice patterns regarding antiplatelet medications for neuro- endovascular stenting in the USA: a multicenter survey. J Neurointerv Surg. 2014;6:774-779.

12. Hochholzer W, Trenk D, Frundi D, Blanke $\mathrm{P}$, Fischer $\mathrm{B}$, Andris $\mathrm{K}$, et al. Time dependence of platelet inhibition after a 600-mg loading dose of clopidogrel in a large, unselected cohort of candidates for percutaneous coronary interven- tion. Circulation. 2005; 111:2560-2564.

13. Gurbel PA, Bliden KP, Zaman KA, Yoho JA, Hayes KM, Tantry US. Clopidogrel loading with eptifibatide to arrest the reactivity of platelets: results of the Clopidogrel Loading With Eptifiba- tide to Arrest the Reactivity of Platelets (CLEAR PLATELETS) study. Circulation. 2005;111:1153-1159.

14. Fefer P, Hod H, Hammerman H, Segev A, Beinart R, Boyko $V$, et al. Usefulness of pretreat- ment with high-dose clopidogrel in patients un- dergoing primary angioplasty for ST-elevation myocardial infarction. Am J Cardiol. 2009;104: 514-518.

15. Leung LY, Albright KC, Boehme AK, Tarsia J, Shah KR, Siegler JE, et al. Short-term bleeding events observed with clopidogrel loading in acute ischemic stroke patients. J Stroke Cerebrovasc Dis. 2013;22:1184-1189.

16. Johnston SC, Easton JD, Farrant M, Barsan W, Battenhouse H, Conwit R, et al. Plateletoriented inhibition in new TIA and inor ischemic stroke (POINT) trial: rationale and design. Int J Stroke. 2013:8:479-483.

17. Nguyen TA, LordkipanidzÉ M, Diodati JG, Palisaitis DA, Schampaert E, Turgeon J, et al. Week-long high-maintenance dose clopidogrel regimen achieves better platelet aggregation inhibition than a standard loading dose before percutaneous coronary intervention: results of a double-blind, randomized clinical trial. J Interv Cardiol. 2009;22:368-377.

18. Patti G, Pasceri V, Mangiacapra F, Colonna G, Vizzi V, Ricottini E, et al. Efficacy of clopidogrel reloading in patients with acute coronary syn- drome undergoing percutaneous coronary inter- vention during chronic clopidogrel therapy (from the Antiplatelet therapy for Reduction of MYocardial Damage during Angioplasty [ARMYDA-8 RELOAD-ACS] trial). Am J Cardiol. 2013;112:162-168.

19. Patti G, Barczi G, Orlic D, Mangiacapra F, Colonna G, Pasceri V, et al. Outcome comparison of 600- and 300-mg loading doses of clopidogrel in patients undergoing primary percutaneous coronary intervention for ST-segment elevation myocardial infarction: results from the ARMYDA-6 MI (Antiplatelet therapy for Reduction of MYocardial Damage during Angioplasty-Myocardial Infarction) randomized study. J Am Coll Cardiol. 2011;58: 1592-1599. 
20. Romo GM, Dong JF, Schade AJ, Gardiner EE, Kansas GS, Li CQ, et al. The glycoprotein Ib-IX-V complex is a platelet counterreceptor for P-selec- tin. J Exp Med. 1999;190:803814.

21. Celi A, Pellegrini G, Lorenzet R, De Blasi A, Ready N, Furie BC, et al. P-selectin induces the expression of tissue factor on monocytes Proc Natl Acad Sci U S A. 1994;91:8767-8771.

22. Siller-Matula JM, Huber K, Christ G, Schror K, Kubica J, Herkner $\mathrm{H}$, et al. Impact of clopidogrel loading dose on clinical outcome in patients un- dergoing percutaneous coronary intervention: a systematic review and metaanalysis. Heart. 2011; 97:98-105.
23. Mangiacapra F, Muller O, Ntalianis A, Trana C, Heyndrickx GR, Bartunek J, et al. Comparison of 600 versus $300-\mathrm{mg}$ clopidogrel loading dose in patients with ST-segment elevation myocardial infarction undergoing primary coronary angio- plasty. Am J Cardiol. 2010;106:1208-1211.

24. Lotrionte M, Biondi-Zoccai GG, Agostoni P, Abbate A, Angiolillo DJ, Valgimigli M, et al. Meta-analysis appraising high clopidogrel loading in patients undergoing percutaneous coronary intervention. Am J Cardiol. 2007;100: 1199-1206.

\section{Corresponding Author}

Pascal Jabbour, M.D.

E: pascal.jabbourajefferson.edu 